\title{
Quantitative Analysis of Liquid by Quick Freezing Into Ice Using Nd-YAG Laser-Induced Atmospheric Plasma
}

\author{
Mohamad Infrawan Yulianto Ichwan, ${ }^{1}$ Hery Suyanto, ${ }^{2}$ Maria Margaretha \\ Suliyanti, ${ }^{3}$ Rinda Hedwig, ${ }^{4}$ Marincan Pardede, ${ }^{5}$ Kiichiro Kagawa, ${ }^{6}$ Tjung Jie Lie, ${ }^{7}$ \\ \& Koo Hendrik Kurniawan ${ }^{7 *}$
}

${ }^{1}$ Department of Physics, Faculty of Mathematics and Natural Sciences, 10 November Institute of Technology, Arief Rahman Hakim, Keputih, Sukolilo, Surabaya 60111, Indonesia. E-mail: infra1730@yahoo.com

${ }^{2}$ Department of Physics, Faculty of Mathematics and Natural Sciences, Udayana University, Bukit Jimbaran, Bali, Indonesia. E-mail: hery6@yahoo.com

${ }^{3}$ Graduate Program in Opto-Electrotechniques and Laser Applications, Faculty of Engineering, University of Indonesia, 4 Salemba Raya, Jakarta 10430, Indonesia. ${ }^{4}$ Hardware Laboratory, Department of Computer Engineering, Bina Nusantara University, 9 KH. Syahdan, Jakarta Barat 11480, Indonesia, E-mail: arindaho@yahoo.com

${ }^{5}$ Department of Electronic Engineering, Faculty of Industrial Technique, University of Pelita Harapan, UPH Tower Lippo Karawaci, Tangerang.

${ }^{6}$ Department of Physics, Faculty of Education and Regional Studies, Fukui University, 9-1 bunkyo 3-chome, Fukui 910, Japan.

E-mail: kagawa@edu00.f-edu.fukui-u.ac.jp

${ }^{7}$ Research Center of Maju Makmur Mandiri Foundation, 40 Srengseng Raya, Kembangan, Jakarta Barat 11630, Indonesia. E-mail: kurnia18@cbn.net.id

\footnotetext{
* author to whom correspondence should be sent and corresponding address: Koo Hendrik Kurniawan, Research Center of Maju Makmur Mandiri Foundation, Kembang Indah III Block G1-21, Puri Indah, Jakarta Barat 11610, Indonesia, Tel: 62-21-5805605, Fax: 62-21-5809144 or 62-21-5867670, E-mail: kurnia18@cbn.net.id
}

Received May 2, 2005. 


\begin{abstract}
A new approach of quantitative analysis of liquid sample using laser ablation technique was developed. The liquid was immediately freezed using the mixture of dry ice and alcohol in weight ratio of $95 \%: 5 \%$. As a result, an increase of the repulsion force from the sample surface will enable the generation of the laser-induced shock wave plasma which was difficult to carry out on liquid surface. The ice sample was then irradiated using Nd-YAG laser operated in its fundamental wavelength. In order to increase the signal to background ratio and to obtain a sharp atomic line spectra, helium gas was used instead of air. Dynamic characterization of the spatially integrated time profile of the $\mathrm{Cu} \mathrm{I} 521.8 \mathrm{~nm}, \mathrm{Cu}$ I $510.5 \mathrm{~nm}$ and $\mathrm{H}_{\alpha}$ lines shows a shock excitation stage and cooling stage which is corresponded to our shock wave model even when the plasma was generated under atmospheric gas pressure. Further study of the time profile averaged temperature of the atmospheric plasma also shows an increase of temperature during the shock excitation stage followed by diminution of temperature during the cooling stage. An application of this technique was then applied to quantitative analysis of several liquid samples. A linear calibration curve which intercept at 0 point was obtained for all of the elements investigated in this study such as sodium, potassium, lithium, copper, silver, lead and aluminum. A detection limit of around $1 \mathrm{ppm}$ was found for the above element. This new technique will contribute to a great extent of laser atomic emission spectrochemical analysis for liquid samples.
\end{abstract}

Keywords: liquid sample; laser-induced shock wave plasma; helium gas; shock excitation stage; cooling stage.

\title{
$1 \quad$ Introduction
}

Recently, there is a rising demand for a low cost, portable and high sensitivity method for the analysis of liquid especially water for rapid field inspection on environmental pollution. In order to detect the important and harmful elements such as heavy and poisonous metals in water, extremely high detection sensitivity is required as those elements are often hazardous even at trace amount. Nowadays, the laser ablation emission spectrochemical analysis (LAESA) method offers the most promising alternative for this purpose because laser ablation is quite suitable for exciting the atoms in all samples form.

There are two main streams in the development of LAESA. The first one adopts a high pressure surrounding gas and is commonly known as laser-induced breakdown spectroscopy (LIBS).$^{1-5}$ In this method, a high power laser with short duration, such as a pulsed Nd-YAG laser, is focused onto a solid, liquid or gas samples under atmospheric pressure. For liquid analysis, the laser is focused directly on water droplet ${ }^{2,6-8}$ or on the water painted on some solid surface. ${ }^{9-10}$ This water analysis technique has been applied to environmental inspection and process control, such as the determination of uranium in solution for nuclear fuel reprocessing. ${ }^{2}$ However, there are several limitations to LIBS technique. 
One of the major limitations is originated from its poor detection limit due to the strong continuous emission background which is inherent to plasma produced at high pressures. Another important limitation is associated with the lack of linearity between the emission intensity of the analytical line and the concentration of the corresponding element in the sample due to the occurrence of self-absorption. Recently, Charfi et $\mathrm{al}^{11}$ have improved the above shortcomings by standardization using Balmer lines of hydrogen emission. However, it should be raised that when the high power laser was directly focused onto the surface of the liquid samples, splashing off of the water should be considered to some extent.

Another line of development in LAESA is undertaken with the use of low surrounding gas pressure. ${ }^{12-15} \mathrm{We}$ have shown in a series of experiments ${ }^{16-20}$ that plasma characteristics favorable to spectrochemical analysis is produced when a pulsed laser, such as $\mathrm{N}_{2}$ laser, ${ }^{16}$ TEA $\mathrm{CO}_{2}$ laser ${ }^{17-18}$ excimer laser, ${ }^{19}$ or Nd-YAG laser $^{20}$ is focused onto a solid target at reduced pressure of around 1-10 Torr. The laser plasma induced in this case generally consists of two distinct parts. The first part is a small high temperature plasma (primary plasma), which gives off an intense continuous emission spectrum for a short time just above the surface of the target. The second part (the secondary plasma) expands with time around the primary plasma, emitting sharp atomic spectral line with negligibly low background signals. On the basis of time-resolved experiments using a TEA $\mathrm{CO}_{2}$ laser ${ }^{17-18}$ and an excimer laser, ${ }^{19}$ we demonstrated that atoms in the secondary plasma were excited by the shockwave, while the primary plasma acted as an initial explosion energy source. We have referred to this method the laser-induced shockwave plasma spectroscopy (LISPS). It was also shown in those previous works that the hardness of the sample was a crucial condition for the plasma generation in LISPS. In other words, LISPS cannot be applied directly to liquid or soft solid samples. We have nevertheless proved that even for soft sample, shockwave plasma was readily produced when a hard subtarget was placed behind them. ${ }^{21-22}$

In order to improve our LISPS technique to liquid sample, recently we have succeeded in applying the laser-induced shockwave plasma spectroscopy (LISPS) for the detection and analysis of metal elements deposited from water sample by means of electrolysis method. It is shown that the elements are generally deposited in the form of thin film on the electrode surface, while the electrode also conveniently serves as a subtarget for the relatively soft metal film, and thereby provides the necessary condition for the generation of shockwave plasma which is favorable for highly sensitive spectrochemical analysis. It is shown that the detection sensitivity of this method reaches it highest value at low surrounding air pressure of around 1 Torr. $^{23}$ 
However, the above technique needs a time consuming pretreatment and the laser used in the experiment is limited to a TEA $\mathrm{CO}_{2}$ laser due to its lower power density so as the evaporation of the subtarget is negligible. This study was substantiated to eliminate the time consuming pretreatment and in order to get sufficient repulsion force from the liquid samples, the liquid was then freezed using a mixture of dry ice and alcohol. It should be noted that the time to freeze the sample is less than 5 minutes in petri-glass with diameter of $30 \mathrm{~mm}$ and height of $5 \mathrm{~mm}$. An excellent linear calibration curve obtained in this study without any internal standardization promises this new technique to be applied in various kind of liquid samples.

\section{Experimental Setup}

Fig. 1 shows part of the diagram of the experimental setup used in this study. A glass container with diameter of $115 \mathrm{~mm}$ in the upper side and $85 \mathrm{~mm}$ in the bottom side was used. The height of the glass chamber was $70 \mathrm{~mm}$. A mixture of dry ice and alcohol with weight ratio of $95 \%: 5 \%$ was used and filled it into the glass chamber until it reaches the surface of the glass chamber. The temperature of the mixture of the dry ice and alcohol was measured using infrared digital thermometer and was to be around $-100{ }^{\circ} \mathrm{C}$. The whole glass was then wrapped using cling wrap in order to avoid the presence of the carbon dioxide gas in the observation region. On top of the cling wrap, a petri-glass with diameter of $30 \mathrm{~mm}$ and height of $5 \mathrm{~mm}$ was placed and inside the petriglass, the liquid to be investigated was poured. It was found that a liquid completely becomes ice within 5 minutes and the temperature of the ice surface was around $-40{ }^{\circ} \mathrm{C}$. In such case the ice samples are ready to be used.

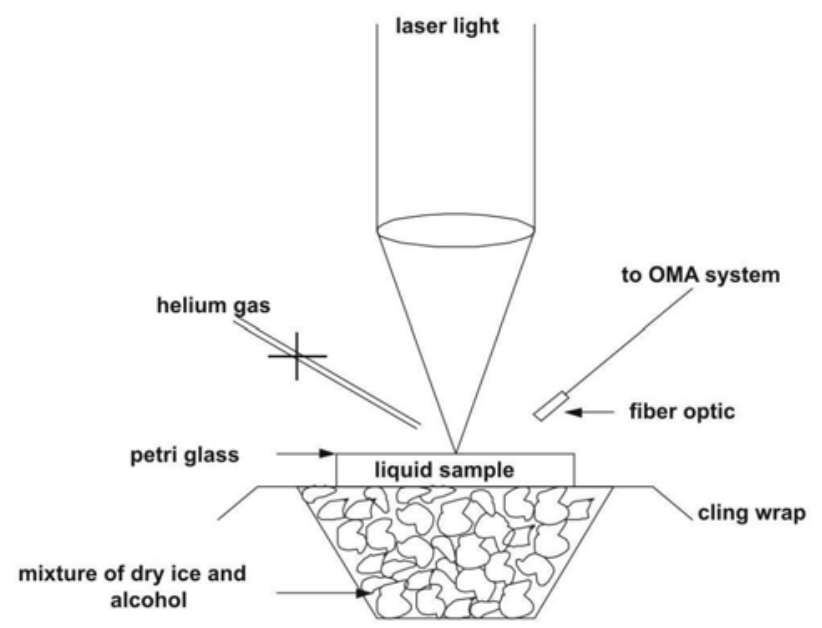

Figure 1 Diagram of the experimental setup. 
The laser radiation from a 1,064 nm Nd-YAG (Quanta Ray, GCR-12S, $400 \mathrm{~mJ}$, $8 \mathrm{~ns}$ ) is operated in a Q-sw mode at $10 \mathrm{~Hz}$ repetition rate with the laser output energy fixed at $250 \mathrm{~mJ}$. The laser beam was focused by a quartz lens ( $\mathrm{f}=150$ $\mathrm{mm}$ ) perpendicular to the ice samples at atmospheric gas pressure as shown in Fig. 1. The shot-to-shot fluctuation of the laser was estimated to be approximately $3 \%$.

Helium gas was flown in the interaction region between the ice samples and laser irradiation. Prior to the data acquisition, the helium gas flow was fixed for $10 \mathrm{l} / \mathrm{min}$ for $5 \mathrm{~seconds}$ in order to completely remove the remain carbon dioxide and air. During the data acquisition, the helium gas was flown at $3 \mathrm{l} / \mathrm{min}$.

The plasma radiation is detected by an optical multichannel analyzer (OMA system, Princeton Instrument IRY-700) attached to a spectrograph with a focal length of $150 \mathrm{~mm}$ and connected to an optical fiber with its entrance placed at a angle of $45^{\circ}$ to the laser beam direction. The distance between the end of the fiber and the interaction region was set at $70 \mathrm{~mm}$. During all of the experiment, the gate delay was set at $1 \mu$ s with gate width of $50 \mu$ s unless otherwise stated. The detector of this measuring system is a gateable intensified photodiode array with gating width ranging from $40 \mathrm{~ns}$ to $80 \mathrm{~ms}$. The spectral window covered by the detector has a width of $80 \mathrm{~nm}$ at $500 \mathrm{~nm}$. The detected signals are monitored on a screen.

\section{Experimental Results and Discussion}

It was reported in our previous works that the hardness of the sample was a crucial condition for the plasma generation in LISPS. In other words, LISPS cannot be applied directly to liquid or soft solid samples. ${ }^{21-23}$ In order to overcome the above problem, we introduced a new technique in which the liquid samples was immediately freezed using a mixture of dry ice and alcohol. It should be noted that the freezing process should be done fast to get a homogeneity in the form of ice sample. However, we faced with a difficulty to keep the ice sample with constant temperature of $-40{ }^{0} \mathrm{C}$ in our vacuum chamber, To that end, experiments were carried out under atmospheric pressure. It is well known that in laser-induced atmospheric plasma known as laserinduced breakdown spectroscopy (LIBS), line broadening takes place to some extent especially for light element such as hydrogen. ${ }^{11}$ In order to escape the above problem, helium gas was used instead of air.

Fig. 2 shows the emission spectra of $\mathrm{H}_{\alpha}$ at different gate delay with gate width set constant at $50 \mu \mathrm{s}$ in (a) air as a surrounding gas at 760 Torr and (b) helium as a surrounding gas at 760 Torr. It is clearly seen that sharp and high efficiency 
emission of the $\mathrm{H}_{\alpha}$ can be obtained under the condition of gate delay of $1 \mu \mathrm{s}$ in the surrounding gas of helium at 760 Torr. Further elucidation of this condition was also clarified using the $\mathrm{H}_{\beta}$ emission line as shown in Fig. 3 in which (a) air as a surrounding gas at 760 Torr and (b) helium as a surrounding gas at 760 Torr was used. The data was taken under the optimum gate delay and gate width of $1 \mu \mathrm{s}$ and $50 \mu \mathrm{s}$, respectively as used in Fig. 2. It should be noted that even rather sharp and high intensity of $\mathrm{H}_{\gamma}$ can still be obtained when helium gas was used as a surrounding gas. To that end, helium gas was used during all of this experiments.
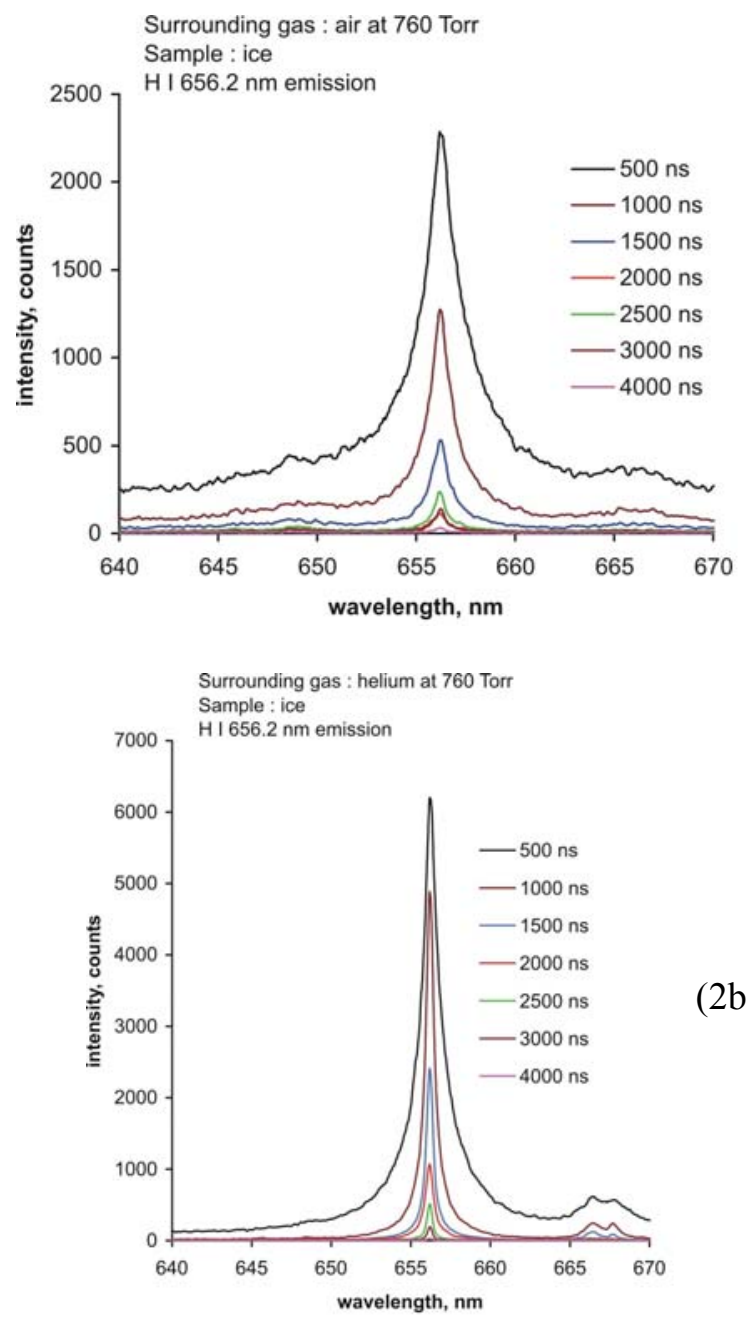

Figure 2 Emission spectra of H I $656.2 \mathrm{~nm}$ in (a) air at 760 Torr and (b) helium at 760 Torr at various gate delay. 


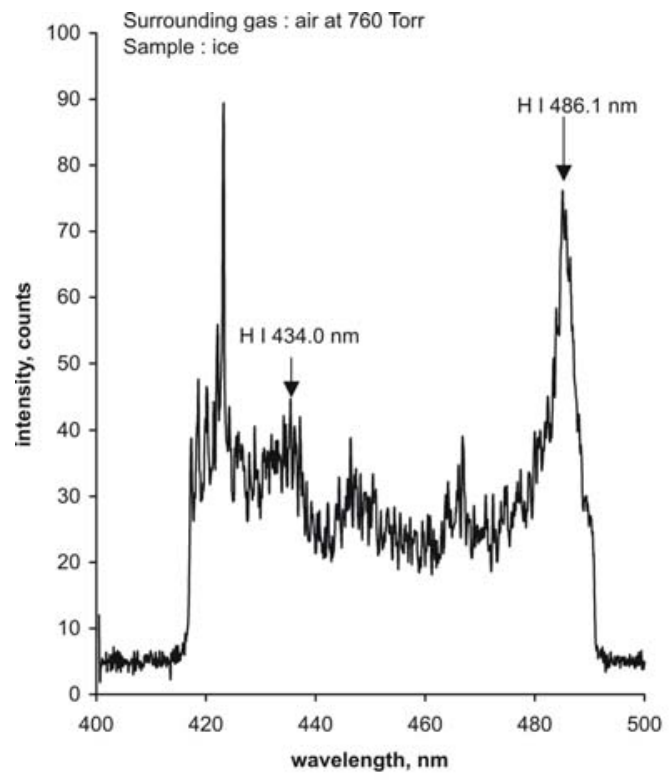

(3a)

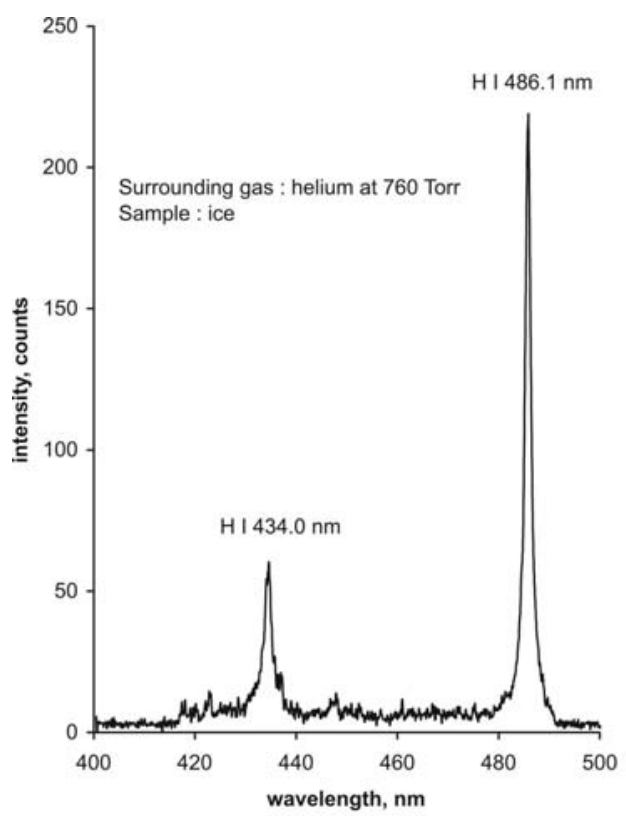

(3b)

Figure 3 Emission spectra of H I $434.0 \mathrm{~nm}$ and H I $486.1 \mathrm{~nm}$ in (a) air at 760 Torr and (b) helium at 760 Torr.

In order to know the excitation mechanism of the generation of laser-induced plasma at atmospheric pressure, the spatially integrated time profile of the emission lines and time profile of averaged temperature of the plasma should be 
taken. Prior to presenting those crucial data, it is noteworthy to recall our previous works in laser-induced plasma generated at low surrounding gas pressure. The excitation mechanism of the ablated atoms in the low pressure surrounding gas has been reported in prior a series of studies in this laboratory. ${ }^{16-20}$ We found that the plasma generated under reduced pressure invariably consists of two distinct parts. The first part, which is called the primary plasma, occupies a small area and gives off an intense continuous emission spectra for a short time just above the surface of the target. The other part, called the secondary plasma, expands with time around the primary plasma with a near hemispherical shape, and emits sharp atomic spectral lines with a negligibly low background. We demonstrated that this secondary plasma was excited by the shock-wave, while the primary plasma acted as an initial explosion energy source. We offered a theory with respect to the excitation mechanism of the secondary plasma as follows. Immediately after the cessation of the primary plasma, atoms gush out from the primary plasma at supersonic speed. It is assumed that the surrounding gas plays the role of a damping material, impeding the free expansion of the propelled atoms, by forming something like a wall against which compression is taking place. As a result of this compression, a blast wave is generated in the surrounding gas. The most important point of the shock wave model is that the energy required to produce the secondary plasma is supplied in the form of kinetic energy from the propelled atoms. By means of this compression, the kinetic energy of the propelled atoms is converted into thermal energy in the plasma, by which atoms are excited.

In a different experiment carried out recently, ${ }^{20,24}$ we proved that, at the initial stage of the secondary plasma expansion, the front of the propelled atoms and the front of the blast wave coincided and moved together with time. However, at a later stage, the front of the atom cluster was separated from that of the blast wave induced in the surrounding gas. In order to further explain the characteristics of the secondary plasma, we presented a hypothetical model, in which the dynamic process of the secondary plasma can be separated into two stages, namely, the shock excitation stage, followed by the cooling stage. Thus, in the shock excitation region, atoms were excited by the heat arising from the strong compression between the shock front and the propelled atoms. The cluster of propelled atoms was proposed to move in a manner somewhat like a piston pushing the surrounding gas. We referred to this stage as the shock excitation stage. Soon afterward, the cluster of atoms began to slow down while loosing their energy to the surrounding gas. As a result, no further excitation took place, since the compression between the shock front and propelled atoms could no longer be sustained due to the widening separation between them, while the cluster of atoms continued to move forward with a residual momentum. Since the surrounding gas behind the shock wave was left with a 
high temperature, and the secondary plasma also contained a large amount of residual thermal energy, the cooling of the plasma was bound to proceed slowly with time. We referred to this part of the process as the cooling stage.

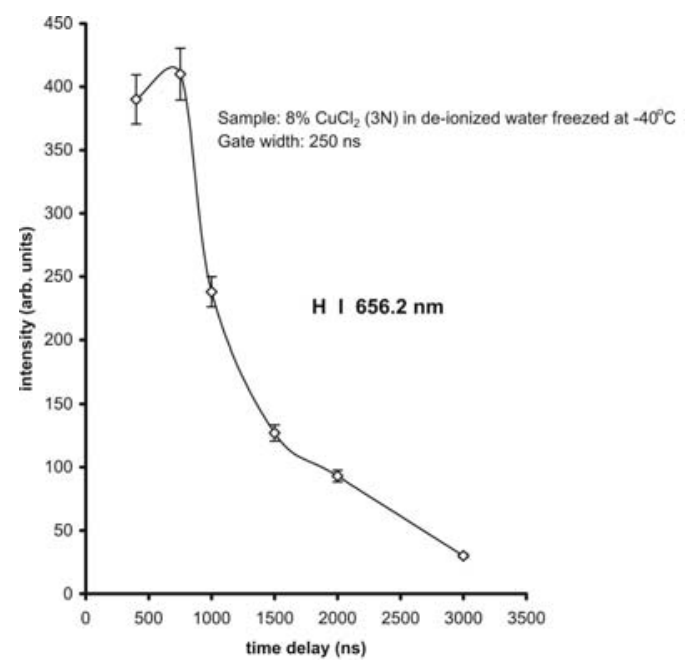

Figure 4 Spatially integrated time profile of H I $656.2 \mathrm{~nm}$ emission line.

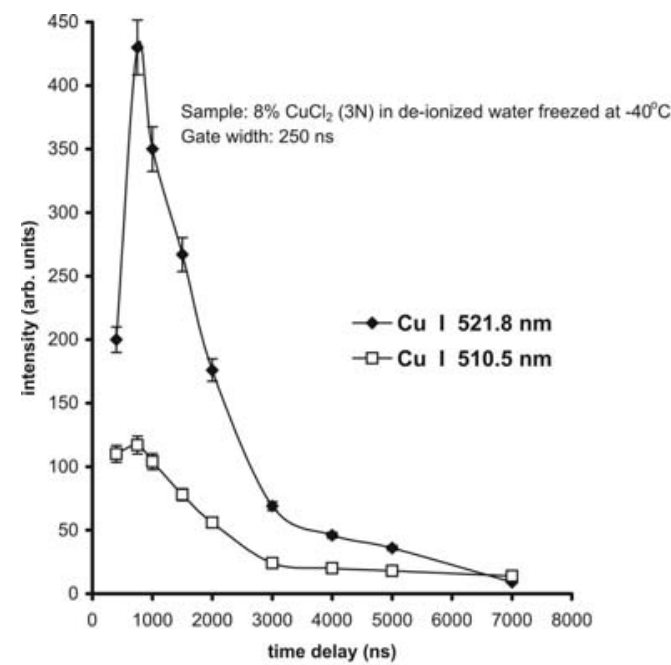

Figure 5 Spatially integrated time profile of $\mathrm{Cu}$ I $521.8 \mathrm{~nm}$ and $\mathrm{Cu}$ I 510.5 $\mathrm{nm}$ emission lines.

In this study we assumed that the excited atom is also excited by the shock wave and to that end the spatially integrated time profile of $\mathrm{H}_{\alpha}$ was taken and the result was presented in Fig. 4. The sample used in this experiment was de- 
ionized water in which $8 \%$ of $\mathrm{CuCl}_{2}$ was added as impurity. The graph in Fig. 4 shows that the emission intensity of $\mathrm{H}_{\alpha}$ increase with time up to $800 \mathrm{~ns}$ and then decay rapidly until 3,000 ns. The behavior of the $\mathrm{H}_{\alpha}$ emission was well compromised with our shock wave model for low pressure plasma. In order to get further explanation of the excitation mechanism of the impurities atoms in water, similar experiment was also carried out and the result is presented in Fig. 5. Fig. 5 shows the spatially integrated time profile of $\mathrm{Cu} \mathrm{I} 521.8 \mathrm{~nm}$ and $\mathrm{Cu} \mathrm{I}$ $510.5 \mathrm{~nm}$. Similar curves were obtained as in the case of $\mathrm{H}_{\alpha}$ emission, namely the emission profiles consist of two components; one is a steep increase observed at the early stage of the plasma expansion and the other is the decline at a lower rate. These emission characteristics are considered to correspond to the shock excitation stage and the cooling stage, respectively; namely, the steep increase is related to the process of continuing compression of the gushed atoms and the decrease at a lower rate is due to the separation between the shock front and the ablated atoms. It is noteworthy to observed that the time it took to reach the maximum emission intensities for $\mathrm{Cu}$ I $521.8 \mathrm{~nm}, \mathrm{Cu} \mathrm{I} 510.5 \mathrm{~nm}$ and $\mathrm{H}_{\alpha}$ is exactly the same at $800 \mathrm{~ns}$. It is then supposed that the hydrogen and copper atoms move at the same speed to form a shock front. This peculiar effect was also reported in our previous works. ${ }^{25-27}$

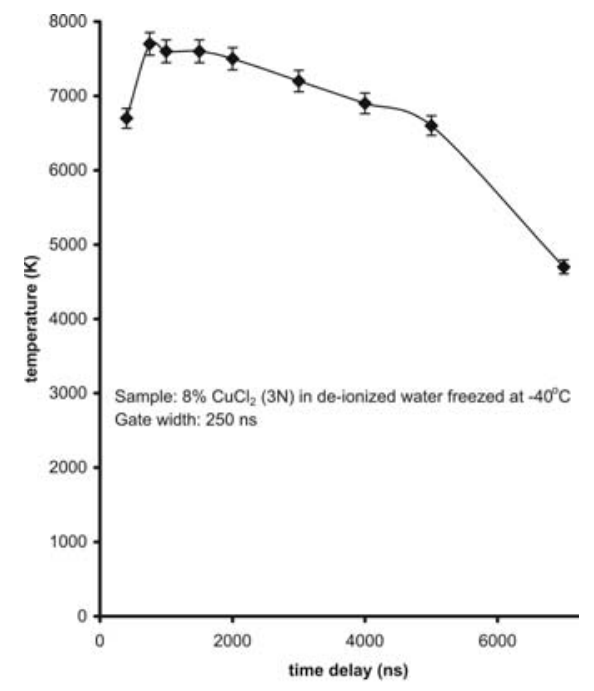

Figure 6 Time profile of the average temperature of the plasma.

In order to make clear the excitation mechanism of the plasma, it is also very useful to know how the temperature of the plasma changes with time after the initiation of the laser bombardment. The plasma temperatures were measured by the Boltzmann two-line method, assuming validity of the Boltzmann 
distribution in the plasma as described elsewhere. ${ }^{20,28}$ In this experiment, the emission intensities, employed for that purpose are those of the $\mathrm{Cu}$ I $521.8 \mathrm{~nm}$ and $\mathrm{Cu}$ I $510.5 \mathrm{~nm}$ spectral lines as shown in Fig. 5.

Fig. 6 shows the time development of the spatially averaged temperature. These data were obtained by using the ratio between the emission intensity of $\mathrm{Cu}$ I $521.8 \mathrm{~nm}$ and that of $\mathrm{Cu} \mathrm{I} 510.5 \mathrm{~nm}$ which are shown in Fig. 5. The maximum temperature of the plasma is closed to $8,000 \mathrm{~K}$. It should also be noted that the pattern of the time profile averaged temperature shows an increase which is corresponded to the shock excitation stage following by a slowly decrease as in the case of cooling stage. This temperature measurement again support our shock wave model in the generation of laser-induced atmospheric plasma instead of gas breakdown model.

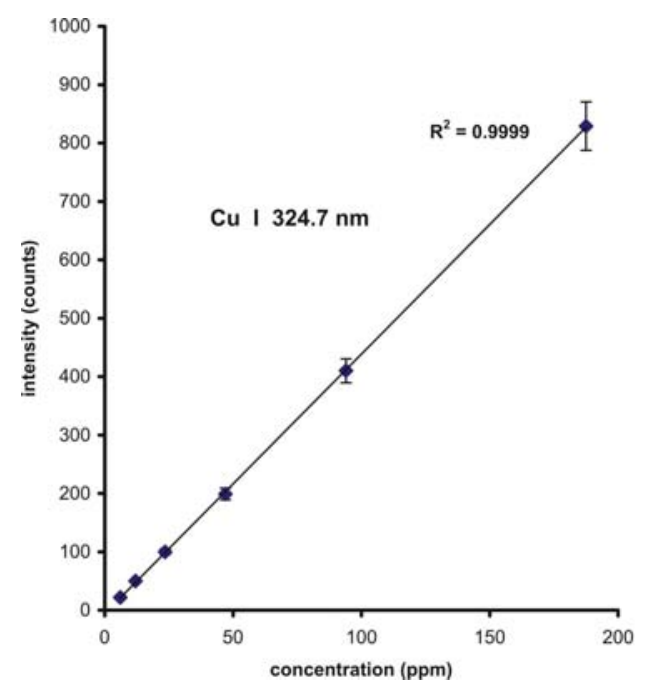

Figure 7 Calibration curve for $\mathrm{Cu}$ I $324.7 \mathrm{~nm}$.

Finally, the application of the laser-induced atmospheric plasma on ice samples was applied for quantitative analysis of several elements. During all of the quantitative experiments, de-ionized water was used as an host element. The gate delay and gate width of the OMA system was set at $1 \mu \mathrm{s}$ and $50 \mu \mathrm{s}$ respectively. The laser energy was fixed at $250 \mathrm{~mJ}$ by means of a set of neutral density filters and helium gas flow was also fixed at $31 / \mathrm{min}$. Figs. 7 till 13 show the calibration curves for $\mathrm{Cu}, \mathrm{Ag}, \mathrm{Pb}, \mathrm{Al}, \mathrm{Li}, \mathrm{Na}$ and $\mathrm{K}$, respectively. It should be noted that all of the calibration curves showed a linear relationship between the emission intensity and its contents and intercept at 0 point. It should also be noted that all of the calibration curves produced good fitting correlation coefficients, which were close to unity. 


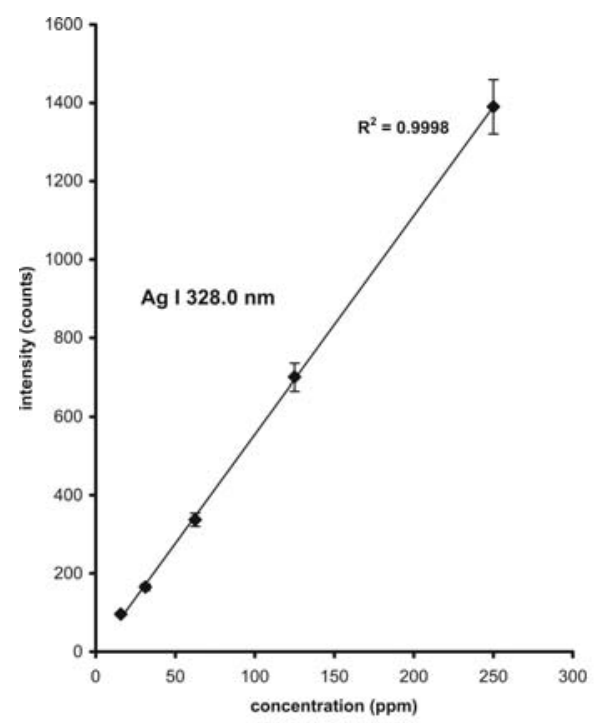

Figure 8 Calibration curve for Ag I $328.0 \mathrm{~nm}$.

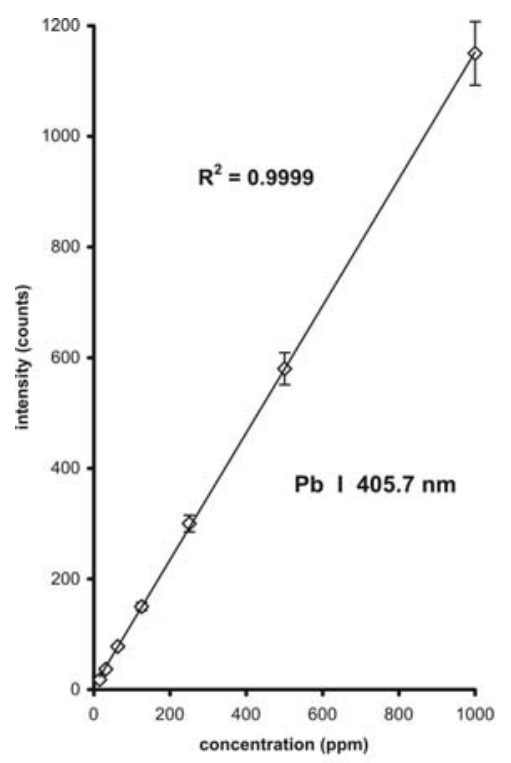

Figure 9 Calibration curve for $\mathrm{Pb}$ I $405.7 \mathrm{~nm}$.

In order to estimate the detection limit of this new technique, a $12 \mathrm{ppm} \mathrm{KBr}$ solution was made and the emission spectra was presented in Fig. 14. Assuming the minimum detectable signal is 3 times of noise ${ }^{1}$, which was measured at wavelength of $765.226 \mathrm{~nm}$ with 1.93 intensity count with background level of 
1.46 intensity count, it was estimated that the detection limit in this stage is around 1 ppm.

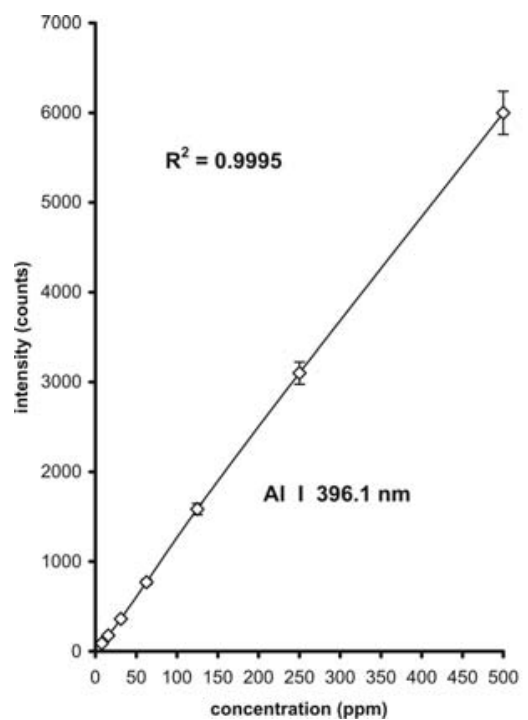

Figure 10 Calibration curve for Al I $396.1 \mathrm{~nm}$.

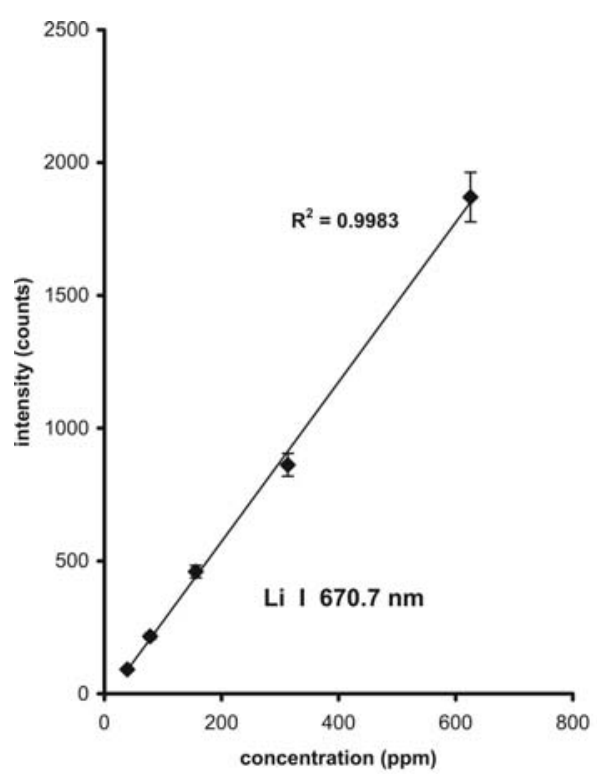

Figure 11 Calibration curve for Li I $670.7 \mathrm{~nm}$. 


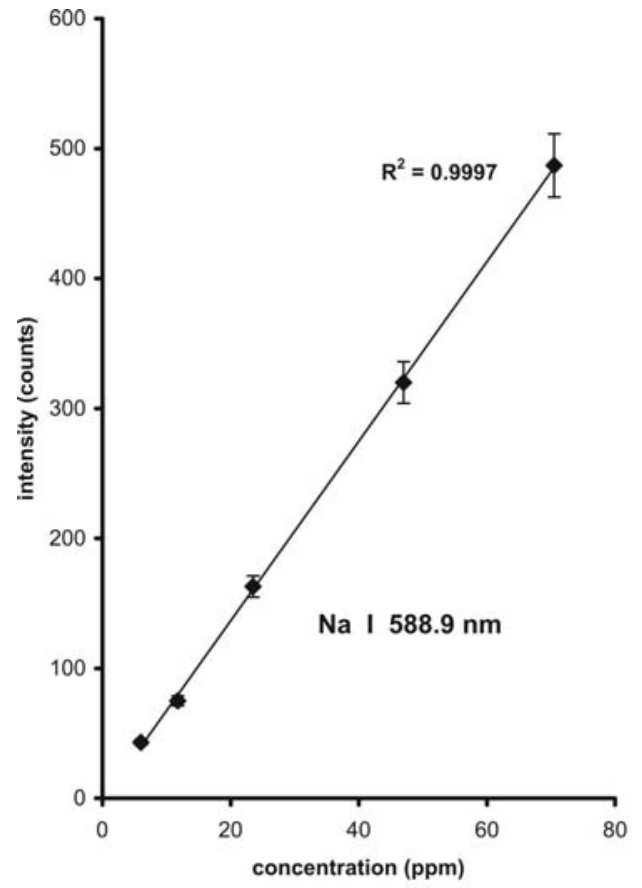

Figure 12 Calibration curve for Na I $588.9 \mathrm{~nm}$.

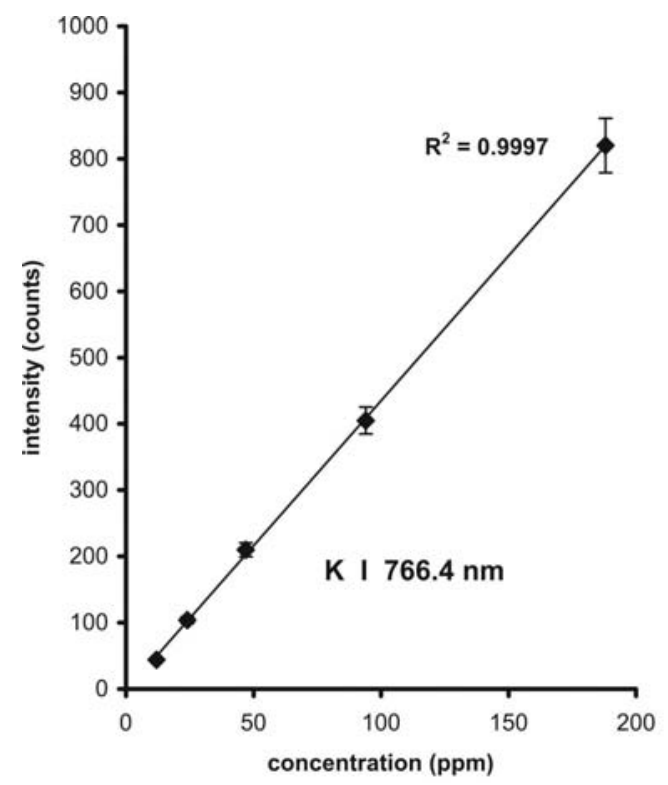

Figure 13 Calibration curve for K I $766.4 \mathrm{~nm}$. 


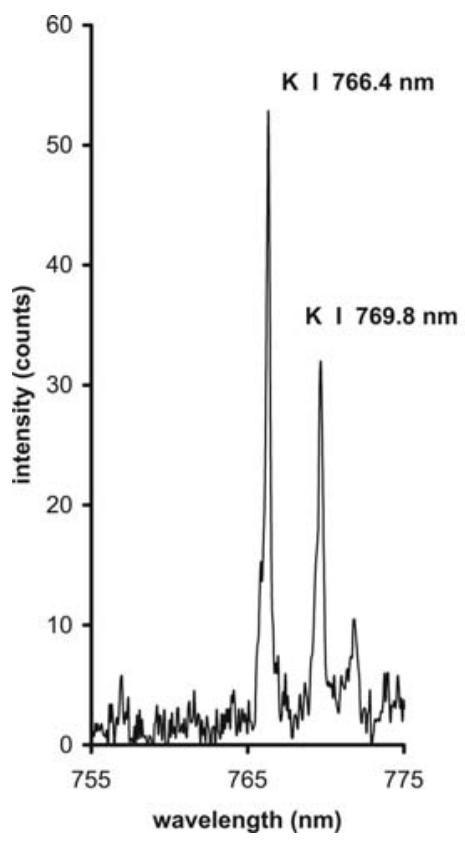

Figure 14 Emission spectra of $12 \mathrm{ppm} \mathrm{KBr}$ sample.

\section{Conclusion}

A unique and creative works for quantitative analysis of liquid samples using laser-induced ablation technique was developed by freezing the liquid samples into ice to get higher repulsion force in producing shock wave plasma. Dynamical characterization of the generated plasma proved beyond any doubt that the plasma generated under atmospheric gas pressure is exactly following the shock wave process instead of well known gas breakdown process. An application of this technique was then applied to quantitative analysis of several liquid samples. A linear calibration curve which intercept at 0 point was obtained for all of the elements investigated in this study such as sodium, potassium, lithium, copper, silver, lead and aluminum. A detection limit of around $1 \mathrm{ppm}$ was found for the above element. Further improvement of this new technique is now in progress in our laboratory by employing high resolution spectrograph to get better detection limit. Application of this new technique will also be carried out to some extent in the environment control such as the detection of polluted and waste water in urban area and the result will be reported elsewhere in the near future. 


\section{Note}

This experimental work was done by Mohamad Infrawan Yulianto ICHWAN as his magister thesis in Graduate Program in Opto Electrotechniques and Laser Applications, The University of Indonesia. He passed away on Aug, 2, 2003. His work was summarized by all of the co-authors dedicated for his excellent performance during his study in University of Indonesia.

\section{References}

1. Cremers, D. A., Radziemski, L. J., in: R.W. Solarz, J.A. Paisner (Eds), Laser Spectroscopy and its Application, Marcel Dekker, New York, 1987, pp.351-415.

2. Yamamoto, K. Y., Cremers, D. A., Ferris, M. J., Foster, L. E., Appl. Spectrosc., 50 (1996) 222.

3. Sabsabi, M. \& Cielo, P., Appl. Spectrosc., 49 (1995) 499.

4. Mao, X. L., Shannon, M. A., Fernandez, A. J. \& Russo, R. E., Appl. Spectrosc., 49 (1995) 1054.

5. Multari, R. A., Foster, L. E., Cremers, D. A. \& Ferris, M. J., Appl. Spectrosc., 50 (1996) 1483.

6. Ito, Y., Ueki, O. \& Nakamura, S., Anal. Chim. Acta., 299 (1995) 401.

7. Nakamura, S., Ito, Y., Sone, K., Hiraga, H. \& Kaneko, K., Anal. Chem., 68 (1996) 2981.

8. Ho, W. F., Ng, C. W. \& Cheung, N. H., Appl. Spectrosc., 51 (1997) 87.

9. Pichahchy, A. E., Cremers, D. A. \& Ferris, M. J., Spectrochim. Acta $\mathbf{B 5 2}$ (1997) 25.

10. Nyga, R. \& Neu, W., Opt. Lett., 18 (1993) 747.

11. Charfi, B., Harith, M. A., Spectrochim. Acta $B 57$ (2002) 1141-1153.

12. Piepmeier, E. H. \& Osten, D. E., Appl. Spectrosc., 25 (1971) 642.

13. Dimitrov, G. \& Gagov, V., Spectrosc. Lett., 10 (1979) 337.

14. Iida, Y., Spectrochim. Acta B45 (1990) 1353.

15. Kuzuya, M. \& Mikami, O., Jpn. J. Appl. Phys., 29 (1990) 1568.

16. Kagawa, K. \& Yokoi, S., Spectrochim. Acta, B37 (1982) 789.

17. Kurniawan, H., Tjia, M., Barmawi, M., Yokoi, S., Kimura, Y. \& Kagawa, K., J.Phys.D: Appl. Phys., 28 (1995) 879.

18. Kurniawan, H., Kobayashi, T. \& Kagawa, K., Appl. Spectrosc., 46 (1992) 581.

19. Kagawa, K., Kawai, K., Tani, M. \& Kobayashi, T., Appl. Spectrosc., 48 (1994).

20. Setia Budi, W., Suyanto, H., Kurniawan, H., Tjia, M.O. \& Kagawa, K., Appl. Spectrosc., 53, 6 (1999) 719.

21. Suliyanti, M. M., Hedwig, R., Kurniawan, H. \& Kagawa, K., Jpn. J. Appl. Phys., 37 (1998) 6628. 
22. Kagawa, K., Lie, T. J., Hedwig, R., Abdulmajid, S. N., Suliyanti, M. M. \& Kurniawan, H., Jpn. J. Appl. Phys., 39, 5A (2000) 2643.

23. Pardede, M., Kurniawan, H., Tjia, M. O., Ikezawa, K., Maruyama, T. \& Kagawa, K., Appl. Spectrosc. 55, 9 (2001) 1229.

24. Kurniawan, H., Lahna, K., Lie, T. J., Kagawa, K. \& Tjia, M. O., Appl. Spectrosc., 55, 1 (2001) 92.

25. Marpaung, A. M., Pardede, M., Hedwig, R., Kurniawan, H., Lie, T. J. \& Kagawa, K., Jpn. J. Appl. Phys., 39, 6B (2000) L601.

26. Marpaung, A. M., Hedwig, R., Pardede, M., Lie, T.J., Tjia, M. O., Kagawa, K., Kurniawan, H., Spectrochim. Acta Part B; At. Spectrom. B55, 10 (2000) 1591.

27. Marpaung, A. M., Kurniawan, H., Tjia, M. O. \& Kagawa, K., J. Phys. D: Appl. Phys. 34, 5 (2001)758.

28. Sabsabi, M., Cielo, P., Appl. Spectrosc. 49 (1995) 499. 